\title{
PROTOTIPE INSTALASI PENERANGAN RUMAH PINTAR UNTUK APARTEMEN TIPE STUDIO BERBASIS MIKROKONTROLER
}

\author{
Okke Dwi Wibowo ${ }^{1}$, Irzan Zakir ${ }^{2}$, Aris Sunawar ${ }^{3}$ \\ PendidikanTeknikElektro, FakultasTeknik, UniversitasNegeri Jakarta \\ ${ }^{1}$ E-mail:okkedwiwibowo@gmail.com
}

\begin{abstract}
This study aims to create an automated system to turn off and turn on the lights. This research used experimental method. This prototype uses Arduino Mega 2560 with the programming language C language simplified with software IDE 1.5.4. an input device consists of three sensor Receiver Passive Infrared (PIR), 1 sensor Microphone (Voice), 1 sensor Radio Frequency Identification (RFID), and 1 sensor Light Dependent Resistance (LDR). Hardware output consists of 5 LED lights air conditioning and Solenoid. PIR is used to detect human presence, Voice sensor is used to turn on and turn off the room lights with applause, RFID sensors are used to unlock which is connected with the solenoid, LDR sensor is used to turn on and off lights that exist outside the home. The results obtained are the PIR sensor can only read infrared moving, RFID can not be read when unobstructed metal objects (iron) and LDR sensor works based on the intensity of light around, so it can be concluded that a prototype installation of lighting smart homes to apartment studio type microcontroller based, tools and systems can work in accordance with well-designed.

Keywords: Arduino Mega 2560, Passive Infrared Receiver, Microkontroler, Radio Frequency Identification,
\end{abstract} Light Dependent Resistance, Solenoid

\begin{abstract}
Abstrak
Penelitian ini bertujuan membuat sistem otomatis dalam mematikan dan menghidupkan lampu. penelitian ini menggunakan metode eksperimen.Prototipe ini menggunakan Arduino Mega 2560 dengan bahasa pemrograman yaitu bahasa $\mathrm{C}$ yang disederhanakan dengan software IDE 1.5.4. peralatan input terdiri dari 3 sensor Passive Infrared Receiver (PIR), 1 sensor Microphone (Suara), 1 sensor Radio Frequency Identification (RFID), dan 1 sensor Light Dependent Resistance (LDR).Peralatan output terdiri dari 5 lampu LED AC dan Solenoid. PIR digunakan untuk mendeteksi keberadaan manusia, sensor Suara digunakan untuk menghidupkan dan mematikan lampu kamar dengan tepukan tangan, sensor RFID digunakan untuk membuka kunci yang disambungkan dengan solenoid, sensor LDR digunakan untuk menghidupkan dan mematikan lampu yang ada diluar rumah. Hasil yang telah didapat adalah sensor PIR hanya dapat membaca infrared yang bergerak, RFID tidak dapat membaca bila terhalang objek logam (besi) dan sensor LDR bekerja berdasarkan intensitas cahaya disekitar,sehinggadapatdisimpulkanbahwaprototipe instalasi penerangan rumah pintar untuk apartemen tipe studio berbasis mikrokontroler, alat dan sistem dapat bekerja sesuai dengan yang dirancang.
\end{abstract}

Kata Kunci : Arduino Mega 2560, Passive Infrared Receiver, Microkontroler, Radio Frequency Identification, Light Dependent Resistance, Solenoid.

\section{PENDAHULUAN}

Seiring perkembangan zaman, kesibukan manusia menjadi semakin meningkat. Untuk itu dibutuhkan cara yang efisien dalam melaksanakan semua aktivitasnya. Banyak cara dilakukan manusia untuk dapat menghemat waktu dan tenaga dalam melakukan aktivitasnya. Salah satu caranya adalah dengan memanfaatkan teknologi yang sudah ditemukan.

Teknologi sudah ada sejak zaman dahulu kala. Teknologi yang pertama ada di bumi adalah teknologi jungkit. Yaitu alat yang digunakan untuk memindahkan batubesar. Seiring berjalannya waktu manusia berpikir untuk dapat membuat banyak hal yang dapat memudahkan suatu kegiatan.

Penemuan listrik merupakan penemuan yang luar biasa sehingga dapat memajukan peradaban manusia. Setelah ditemukan nya listrik, kemudian banyak ditemukan alat-alat yang dapat membantu aktivitas manusia seperti system kendali otomatis.

Sistem kendali secara otomatis di bidang ilmu pengetahuan dan teknologi belakangan ini berkembang dengan pesat. Dengan adanya kemajuan di bidang ilmu pengetahuan dan 
teknologi menghasilkan inovasi baru yang berkembang menuju lebih baik. Hal ini dapat dilihat dari jangkauan aplikasinya mulai dari rumah tangga hingga peralatan yang canggih. Rumah atau tempat tinggal merupakan salah satu kebutuhan dasar bagi manusia (primer) disamping kebutuhan sandang dan pangan. Dikatakan sebagai kebutuhan dasar (basic human needs) karena merupakan unsur yang harus dipenuhi guna menjamin kelangsungan hidup manusia. Dimana kebutuhan dasar ini akan menentukan taraf kesejahteraan sekaligus kualitas hidup manusia itu sendiri karena itu suatu hunian pada hakekatnya dapat berpengaruh terhadap kualitas kehidupan orang-orang yang tinggal di dalamnya.

Pada dasarnya rumah saat ini masih menggunakan system pengendalian instalasi secara manual, dimana manusia masih diharuskan menghidupkan sakelar terlebih dahulu ketika akan memasuki sebuah ruangan dan harus mematikan sakelar bila ingin meninggalkan tempat tersebut. Tetapi saat ini sudahbanyak model rumah yang sudah menggunakan sistem pengendalian instalasi penerangan secaraotomatis, seperti contohnya pada apartemen yang saat ini sudah banyak menggunakan system otomatis dalam penerangan lampunya, apabila manusia akan melewati suatu tempat tidak perlu lagi harus menghidupkan saklar lampu secara manual untuk mendapatkan pencahayaan yang cukup.

Untuk mengatasi masalah tersebut, perlu adanya sistem kontrol otomatis yang digunakan untuk mengoperasikan instalasi, dengan cara membuat system instalasi otomatis. Sistem pengoperasian instalasi otomatis bekerja pada saat manusia memasuki suatu tempat dan ruangan atau membuka dan menutup pintu ruangan.

Biasanya sering kali manusia beraktifitas di suatu tempat, setelah menyalakan lampu ruangan terkadang lupa untuk mematikannya kembali, dan seringnya lampu yang dihidupkan dari malam hari ketika sudah pagi lupa untuk dimatikan. Oleh karena itu perlu adanya sistem yang mengatur agar nyala lampu di dalam ruangan atau suatu tempat dapat mati atau nyala sesuai kebutuhan manusia saja.
Di sisi lain telah ditemukan suatu alat mengendalikan lampu secara otomatis, menggunakan pengendali yang murah dan mudah digunakan yaitu Arduino mega 2560. Selain itu juga sudah banyak sensor cahaya light dependent resistor (LDR), sensor gerak Passive infrared Receiver (PIR), sensor suara (Microphone) yang beredar di pasaran yang dapat menjadi masukan atau perintah dalam pengoperasian lampu secara otomatis. Oleh karena itu perlu dicoba memanfaatkan komponen-komponen tersebut untuk membuat prototype instalasi penerangan rumah otomatis berbasis Arduino Mega 2560. Penulis memilih membuat prototype tersebut karena akan sangat memudahkan manusia dalam melintasi dan memasuki tempat.

Prototipe adalah bentuk fisik pertama dari satu objek yang direncanakan dibuat dalam satu proses produksi, mewakili bentuk dan dimensi dari objek yang diwakilinya dan digunakan untuk objek penelitian dan pengembangan lebih lanjut.

\section{METODE}

Menurut Sugiyono (2010:2) Metode penelitian merupakan suatu cara dalam menganalisis data. Menurut Sugiyono, Metode Penelitian pada dasarnya merupakan cara ilmiah untuk mendapatkan data dengan tujuan dan kegunaan tertentu.

Metode yang digunakan dalam penelitian ini adalah metode eksperimen analisis dengan pendekatan kuantitatif. Menurut Sugiyono (2012:109) metode eksperimen merupakan metode penelitian yang digunakan untuk mencari pengaruh perlakuan tertentu terhadap yang lain dalam kondisi yang terkendalikan. Metode penelitian eksperimen adalah metode penelitian kuantitatif. Disini masalah yang dibahas oleh penulis adalah mengatasi seringnya manusia lupa dalam mematikan lampu ketika sudah tidak ada aktifitas didalamnya atau lupa ketika terbangun disiang hari sehingga lampu menyala terus menerus dan dari masalah yang sudah ditentukan diharapkan penulis dapat menemukan perlakuan dan pengaruh yang bisa merubah masalah kondisi tersebut. Beberapa tahapan untuk membuat alat prototipe dapat dilihat pada gambar 1. 


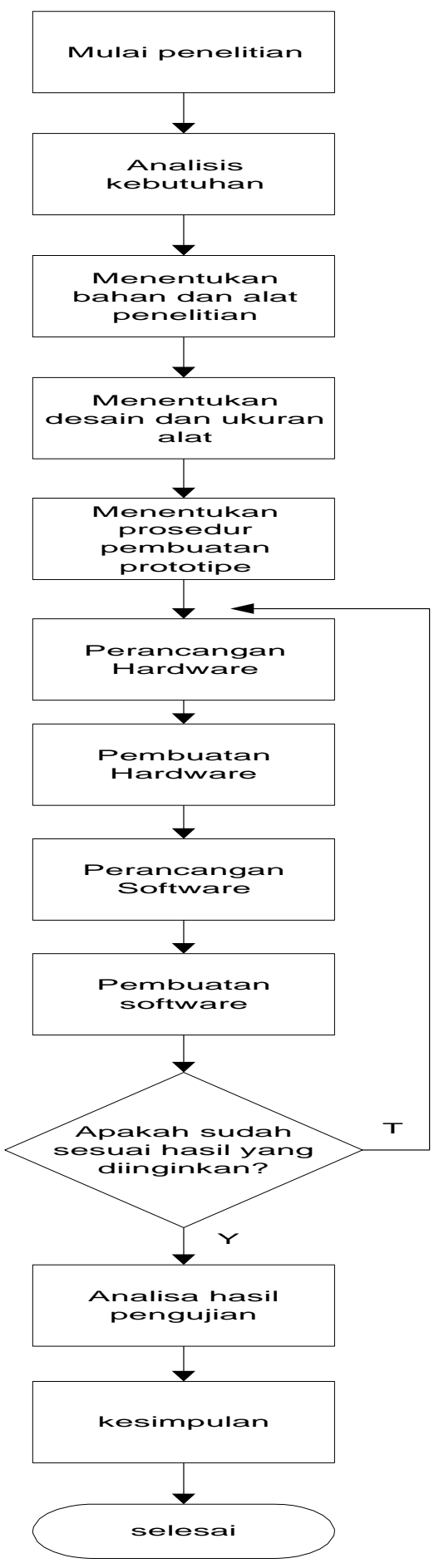

Gambar 1. Diagram alir penelitian

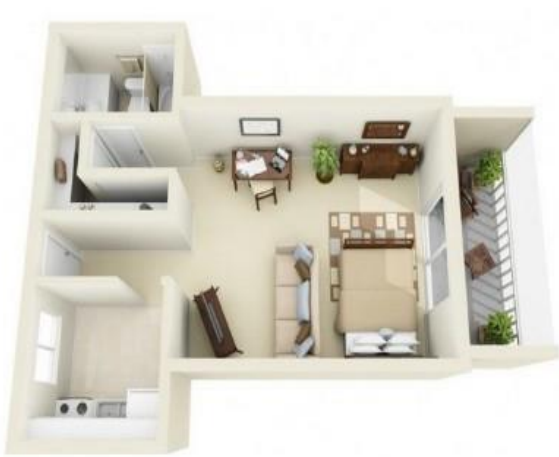

Gambar 2. Desain Prototipe

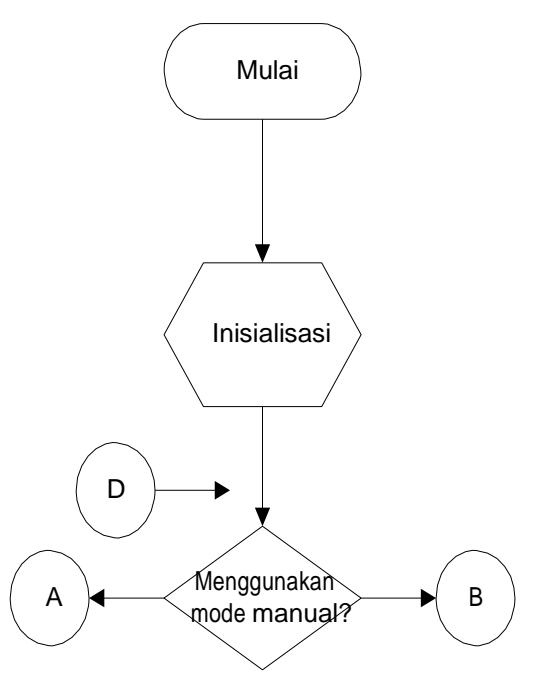



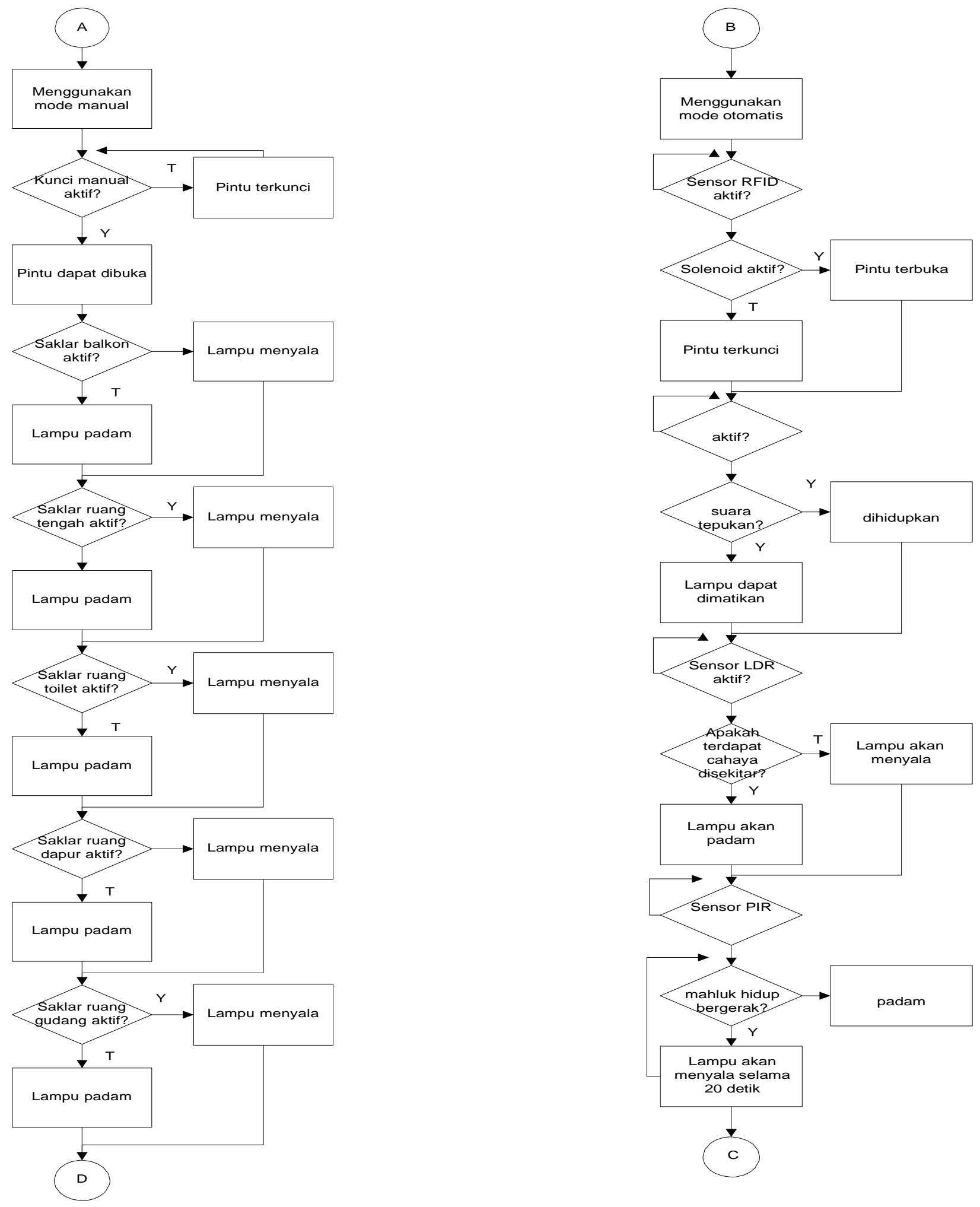


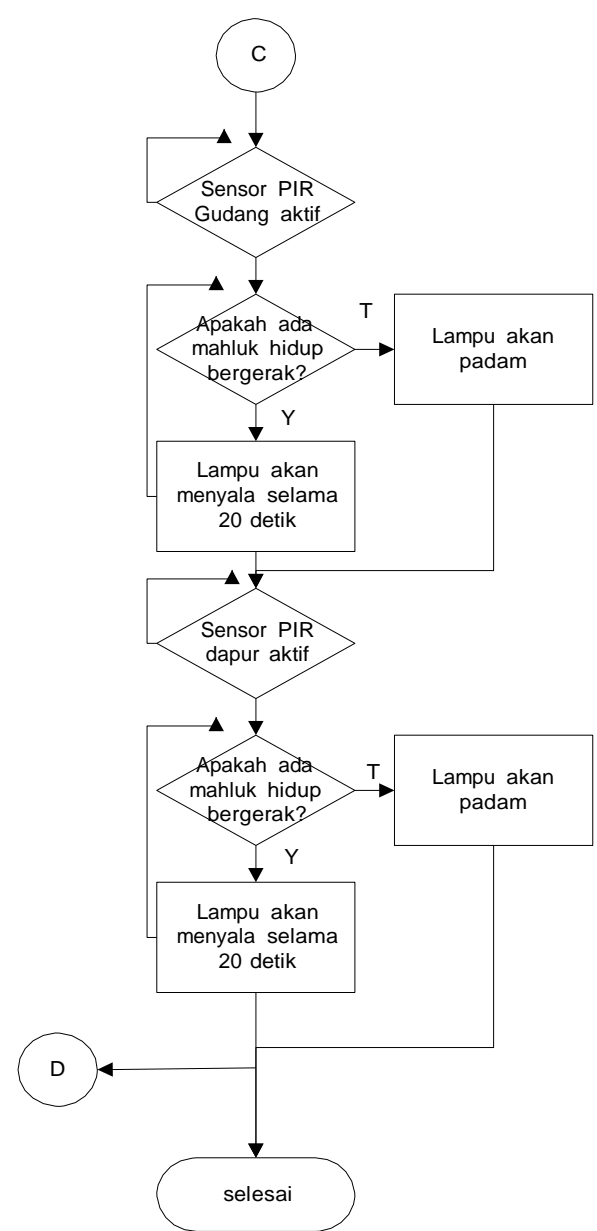

Gambar 3. Flowchart Sistem Alat

\section{HASIL DAN PEMBAHASAN}

PIR (Passive Infrared Receiver)

Hasil pengujian ini dilakukan dengan membuat program dan rangkaian menggunakan controller arduino mega 2560 dan sensor PIR

mendeteksi gerakan dan keberadaan manusia dengan membaca sensor infrared pada mahluk tersebut, sensor yang digunakan berjumlah tiga unit yang dimana sensor tersebut diaplikasikan di tiga tempat berbeda yaitu di dapur, kamar mandi (toilet) dan gudang. Sensor akan mendeteksi keberadaan manusia dengan mendeteksi adanya gelombang atau gerakan dari mahluk hidup sehingga dapat di asumsikan bahwa ruangan tersebut sedang dimasuki mahluk hidup atau terdapat gerakan makhluk hidup didalamnya.

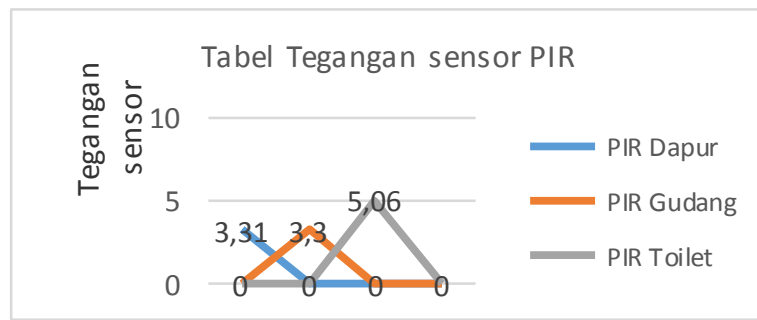

Gambar 4. Tabel Tegangan Sensor PIR

\section{Sensor Suara (Microphone)}

Hasil pengujian ini dilakukan dengan membuat program dan rangkaian menggunakan controller arduino mega 2560 dan sensor suara yang digunakan untuk mendeteksi suara di kamar tidur atau ruang tengah dengan cara membaca gelombang suara yang dikeluarkan dari tepukan tangan manusia berupa gelombang suara. Sehingga dapat di asumsikan bahwa ruangan tersebut sedang dimasuki mahluk hidup didalamnya.

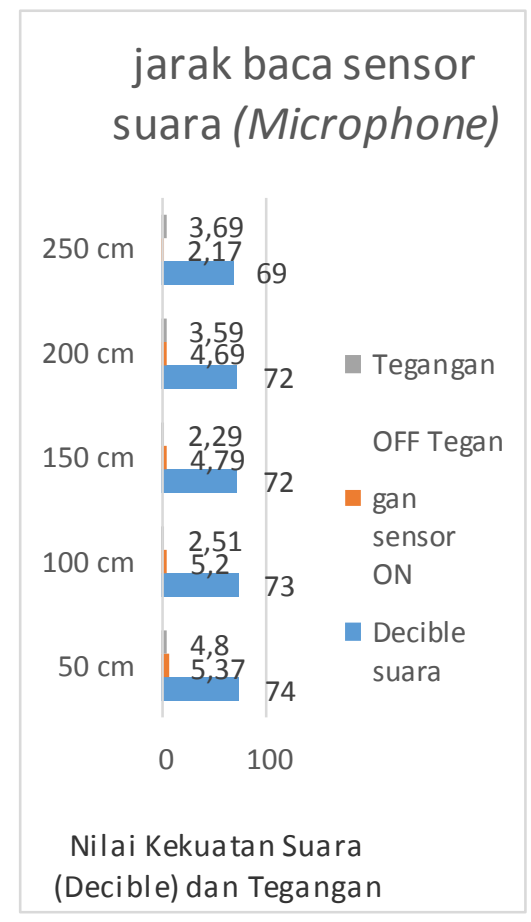

Gambar 5. Jarak Baca Sensor Suara

\section{LDR (Light Dependent Resistance)}

Hasil pengujian ini dilakukan dengan membuat program dan rangkaian menggunakan controller arduino mega 2560 dan sensor LDR (Light Dependent Resistance) yang digunakan untuk mendeteksi cahaya, sensor tersebut ditaruh di bagian luar rumah sehingga memperoleh data cahaya yang dibutuhkan. Sehingga diasumsikan ketika menerima atau tidak menerima cahaya 
nantinya sensor tersebut dapat digunakan untuk mematikan dan menghidupkan lampu pada bagian luar rumah atau balkon.

\section{Tegangan Lampu}

Hasil pengujian ini dilakukan dengan membuat rangkaian instalasi yang masing masing lampunya dihidupkan menggunakan sensor (passive infrared receiver, microphone, light dependent resistance) lampu akan bekerja ketika sensor bekerja atau lampu dihidupkan menggunakan saklar.

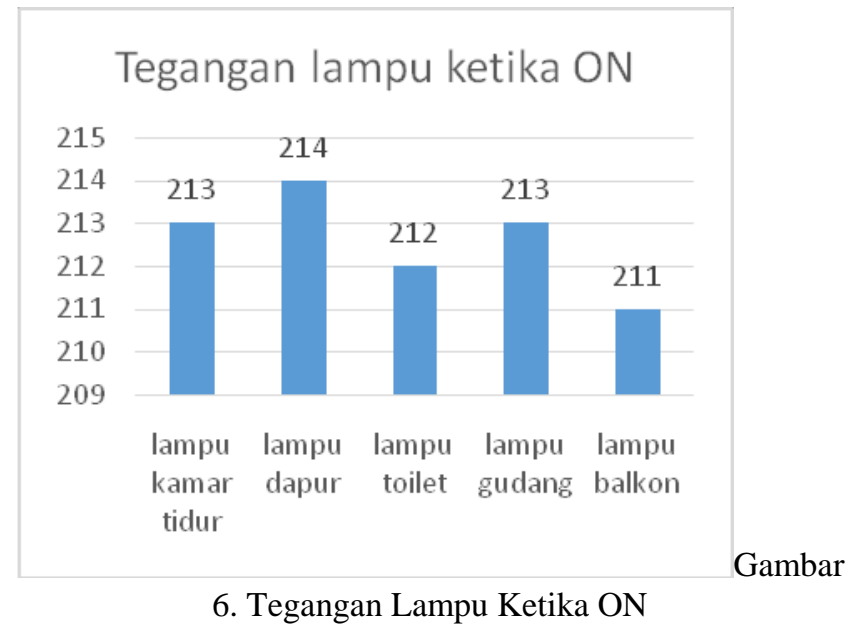

\section{KESIMPULAN DAN SARAN}

\section{Kesimpulan}

Setelah dilakukan penelitian dengan membuat sebuah prototipe instalasi penerangan rumah pintar untuk apartemen tipe studio berbasis mikrokontroler, maka kesimpulan yang didapat adalah penerangan pada sistem rumah pintar dengan menggunakan sensor (PIR, LDR dan Microphone) sebagai pengendali untuk menghidupkan dan mematikan lampu secara otomatis telah berhasil diterapkan untuk kehidupan sehari hari.

\section{Saran}

a. Bagian dalam prototipe masih terkesan kurang rapi karena kecilnya ukuran prototipe dan banyaknya kabel serta komponen yang sulit disembunyikan sehingga masih terlihat kurang rapi. Oleh karena itu perlu dibuat prototipe yang lebih besar dan disediakan tempat khusus untuk wadah rangkaian elektronikanya.

b. Pada sensor suara (Microphone) bisa digunakan sensor suara (Voice) agar pembacaan gelombang suara ketukan bisa diganti menggunakan pembacaan gelombang suara (per-kata).

c. Pada perangkat mikrokontroler dapat menggunakan PLC sebagai pengendali program.

\section{DAFTAR PUSTAKA}

Dinata, Yuwono Marta. (2015). ArduinoItuMudah. Jakarta: PT. Elex Media Komputindo.

FakultasTeknik. 2009. BukuPedomanSkripsi /Komprehensif / KaryaInovatif(S1). Jakarta: FakultasTeknik, UniversitasNegeri Jakarta.

Irawan. (2012). MembuatAplikasi Android untuk Orang Awam. Palembang.

Kadir, Abdul. (2012). PanduanPraktisMempelajariAplikasiMikroko ntrolerdanPemrogramannyaMenggunakanAr duino. Yogyakarta: AndiMaxikom

Sugiyono. (2012). Metode Penelitian Kuantitatif, Kualitatif dan Kombinasi (Mixed Methods). Bandung : Alfabeta, CV.

http://kip.bppt.goid/index.php/prototipe/definisialih-teknologi. Diakses pada tanggal 4 Desember pukul 14.25 WIB

http://saluky.blogspot.co.id/2013/03/pengertianprototype.html. Diakses pada tanggal 4 Desember pukul 15.15 WIB

http://www.lamudi.co.id/journal/rumah-pintarjadi-konsep-rumah-masa-depan/diakses pada tanggal 5 Desember 2015, pukul 13.00 WIB

http://komponenelektronikagratis.blogspot.co.id/ 2014/01/sensor-suara.html diakses pada tanggal 5 Desember 2015, pukul 13.10 WIB

https://en.wikipedia.org/wiki/Microphone siakses pada tanggal 5 Desember, pukul 13.16 WIB 
https://bagusrifqyalistia.wordpress.com/2008/12/ 12/cara-kerja-sensor-pir/ diakses pada tanggal 5 Desember 2015, pukul 13.42 WIB

https://bagusrifqyalistia.wordpress.com/2008/12/ 12/cara-kerja-sensor-pir/ diakses pada tanggal 6 Desember 2015, pukul 09.10 WIB

http://www.iseerobot.com/produk-1052-sensorgerak-pir.html diakses pada tanggal 6 Desember 2015, pukul 10.01 WIB 